\title{
Special Theme: Modelling of Manufacturing Processes
}

\author{
Uday S. Dixit ${ }^{1} \cdot$ Swarup Bag $^{1}$
}

Received: 11 August 2016/Accepted: 11 August 2016/Published online: 3 September 2016

(C) The Institution of Engineers (India) 2016

Manufacturing sector is the backbone of the economic development of our nation. There is an increasing emphasis on this sector through the "Make in India" program of Indian Government. Two major challenges for the industry are to achieve the goal of sustainability and face stiff global competition. It is pertinent, therefore, to apply scientific methods in manufacturing with a focus on reducing energy consumption, pollution, resources and cost. This needs proper attention for entire manufacturing system including supply chain. However, the most difficult task is to optimize the manufacturing processes. This requires proper modelling of the processes. The modelling of manufacturing processes requires the application of material science, plasticity, heat transfer, fluid mechanics, thermodynamics and several other areas of physics and chemistry. The governing differential equations of a manufacturing process are solved using some numerical techniques such as Finite Difference Method (FDM), Finite Element Method (FEM), and Finite Volume Method (FVM).

The research in the modelling of manufacturing process comprises the development of suitable governing equations of the process as well as their solution. It invariably requires the experimental validation. It is important to understand the validity of assumptions and the constraints of the shopfloor. It is encouraging to note that manufacturing fraternity is recognizing the importance of modelling of manufacturing processes. This is reflected from a large

Uday S. Dixit

usd1008@yahoo.com

1 Department of Mechanical Engineering, Indian Institute of Technology Guwahati, Guwahati 781039, India number of papers submitted in the prestigious $5^{\text {th }}$ International $\& 26^{\text {th }}$ All India Manufacturing Technology, Design and Research (AIMTDR) Conference held at Indian Institute of Technology Guwahati during December 12-14, 2014. This special issue entitled "Modelling of Manufacturing Processes" contains eight revised and enhanced papers presented in the conference. The papers have been further peer reviewed for publication in the special issue. The papers in the special issue are from casting, traditional and non-traditional machining, forming and welding areas.

The paper "Mathematical Modelling of Solidification in a Curved Strand during Continuous Casting of Steel" describes transport phenomena based heat transfer and fluid flow model of continuous casting process using finite volume method. The turbulent flow of molten materials and metallurgical effect are considered in this study. Through simulation, the authors identified the upper limit of casting speed for avoiding the defects.

The paper "Finite Element Simulations of Micro Turning of Ti-6Al-4V using PCD and Coated Carbide Tools" describes the simulation of micro-turning process over Lagrangian frame where chip formation is modelled by adaptive re-meshing technique. The material model includes strain gradient effect to represent the flow stress of the work material. Polycrystalline diamond (PCD) tool shows better performance than coated carbide in terms of low interface temperature and low power consumption at high cutting speed. The error in the prediction of cutting forces between numerical model and experimental results is less than $15 \%$.

The paper "Finite Element Method based Modeling for Prediction of Cutting Forces in Micro-end Milling" describes the prediction of cutting forces in micro-end milling process by considering the effect of frictional 
behaviour at the chip-tool interface and failure parameters of the workpiece. Johnson-Cook constitutive model is used for the simulation of orthogonal cutting process. The simulated results are compared with experiments and the maximum error in the prediction of tangential force is less than $17 \%$.

In the paper "Simulation of Magnetic Field Assisted Finishing (MFAF) Process Utilizing Smart MR Polishing Tool", the authors have proposed an advanced finishing process capable of producing nano-meter level surface finish. The permanent magnet is used to create required magnetic field along with magneto rheological (MR) fluid as a polishing brush. Assuming laminar and incompressible flow of MR fluid with spherical particles, a numerical model has been developed using FEM. The prediction of surface roughness profile from numerical model matches well with experimental results.

The paper "Modeling of Closed-die Forging for Estimating Forging Load" estimates the forging load using analytical as well as FEM based model. It has been observed that FEM based model provide better prediction compared to slab method based analytical model. The paper "Numerical Modelling of Wire-EDM for Predicting Erosion Rate of Silicon" proposes the slicing of silicon wafer using wire-EDM process. The mathematical model considers the phenomenological effect of plasma channel, melting and erosion of Si material. Erosion rate is experimentally measured and is validated with proposed mathematical model. The crater size and erosion rate decreases and kerf-width increases with the increase in wire diameter. The re-deposition of the eroded material is included through the effect of plasma flushing efficiency.

The paper "Finite Element Analysis of Cross Rolling on AISI 304 Stainless Steel: Prediction of Stress and Strain Fields" presents coupled thermo-mechanical simulation of cross-rolling assuming rigid-viscoplastic behaviour of materials. The simulation has been carried out for several rolling passes. The predicted distribution of stress, strain, and strain are compared with experiments to validate the numerical results. The paper "Finite Element Simulation of Temperature and Strain-distribution during Friction Stir Welding of AA2024 Aluminum Alloy" presents thermomechanical simulation of friction stir welding process. The complex interaction between tool and workpiece are incorporated through contact condition. The temperature simulation is performed both for workpiece and FSW tool. The strain, strain rate, and temperature dependency of flow stress is taken into account.
It is envisaged that the practicing engineers, researchers and students will find these papers informative and stimulating. Some of the findings of these papers may be adopted by industries. However, as the modelling of manufacturing processes is a complex task, continuous research is needed to upgrade the existing models. Modelling may also provide clue to innovation in the manufacturing sector.

We are grateful to Prof. Gautam Biswas, Editor-in-chief of Journal of The Institution of Engineers (India): Series C and Springer for providing us the opportunity to guest-edit this issue. We also thank the authors, reviewers and organisers of AIMTDR 2014. We welcome the feedback about this special issue.

Uday S. Dixit obtained Bachelor's Degree in Mechanical Engineering from erstwhile University of Roorkee (now Indian Institute of Technology Roorkee) in the year 1987. After working for Machine Tools Division of HMT Pinjore, he obtained M.Tech and Ph.D in Mechanical Engineering from Indian Institute of Technology Kanpur in 1993 in 1998, respectively. He has also served in INDOMAG Steel Technology, New Delhi from February 1993 to July 1993, where his main responsibility was to design the hydraulic system of various machines. Prof. Dixit joined the Department of Mechanical Engineering at Indian Institute of Technology Guwahati in the year 1998 where he is currently a Professor and was Head of Department from March 2006 to March 2009. He was also the Officiating Director of Central Institute of Technology, Kokrajhar, India from February 2014 to May 2015. He is actively engaged in carrying out research in the modelling of manufacturing processes for the last 25 years. Prof. Dixit has published about 72 Journal papers, 80 Conference papers, 9 books (as author/editor) and 20 Book chapters related to manufacturing and finite element method. He has guest-edited 10 special issues of journals of international/national repute.

Swarup Bag completed his Bachelors' of Engineering in Mechanical Engineering from the Jalpaiguri Government Engineering College, Jalpaiguri, West Bengal, India in the year 2000, Masters in Mechanical Engineering in 2002 from Indian Institute of Engineering Science and Technology, Shibpur, West Bengal, India (which was known as Bengal Engineering College, Shibpur, India) in the year 2002 and Ph.D on "Development of Bi-directional Heat Transfer and Fluid Flow Model for Reliable Design of GTA and Laser Welding Processes" in 2009 from Indian Institute of Technology Bombay, Mumbai, India. Later he has worked at the Center for Material Forming (CEMEF), MINES Paris Tech, France for 20 months in Metallurgy, Structure and Rheology (MSR) group. In the year 2011, he joined the Department of Mechanical Engineering, Indian Institute of Technology Guwahati as a faculty member. His primary area of research is fundamental process modelling of welding and joining technologies, optimization of manufacturing processes and recrystallization in metal forming processes. Dr. Bag has published about 37 journal papers, 34 Conference papers, and 7 book chapters related to manufacturing processes. He is the author of the book 'Computational models for GTA and laser welding processes' and recipient of 'Royal Arc Award 2009' from Indian Institute of Welding for the best PhD thesis in welding. 